Štefan Barbarič

\title{
STIK PRIMOŽA TRUBARJA Z MISLIJO ERAZMA ROTTERDAMSKEGA
}

V komaj pregledni vrsti študij in razprav o slovenski protestantski književnosti in kljub novim ter ponovnim obravnavam ostaja vprašanje, kako je evropska humanistična misel odmevala $\mathrm{v}$ delih Trubarja in ostalih piscev, še nadalje $v$ mnogočem neobdelano in nezadovoljivo pojasnjeno. Na to vrzel je - v vrsti drugih - pokazal že Mirko Rupel v jubilejnem zapisu ob 400 -letnici slovenske knjige, ${ }^{1} \mathrm{v}$ katerem je pretresel stanje predmetnega znanstvenega raziskovanja. Vendar vrzeli tudi poznejša znanstvena publicistika ni zapolnila. Na to sta opozorila ocenjevalca slovenskih literarnoslovstvenih pregledov: Dušan Pirjevec ${ }^{2}$ je v Ruplovem orisu protestantske književnosti pogrešal oznako duhovne usmerjenosti Bonoma in drugih italijanskih humanistov, ki jih je Trubar lahko spoznal v času bivanja $\mathrm{v}$ Trstu; in Janko Kos, ki je v analitičnem pretresu Stari in novi pogledi na slovensko slovstvo ${ }^{3}$ sodil,

da tudi v najnovejših sintetičnih delih našega slovstvenega zgodovinopisja ni najti določnejše, kaj šele dokončne besede o vlogi evropskega humanizma v slovenskem kulturnem prostoru 16. stoletja.

Po njegovi sodbi tudi novejši literarnozgodovinski pregledi niso uspeli, da bi prepričljivo odgovorili na vprašanje, kakšen pomen pripada vplivu dunajskega, zlasti pa še, kašne so razsežnosti vplivanja predreformacij-

1 Reformacija in naša literarna zgodovina, Slavistična revija, IV/1951, str. 67/68.

2 Zgodovina slovenskega slovstva (oc.) Naša sodobnost, V/1957, str. 364/365.

3 II, Sodobnost, XVIII/1970, str. 524 s. 
skega Erazmovega in reformacijskega Melanchthonovega humanizma. Kritik meni, da so v delih, ki jih je vzel v razvid, ti vplivi ostali nezadovoljivo predstavljeni, ker pač niso bili predhodno podrobno raziskani, deloma pa zavoljo tega, ker

še zmeraj nismo sposobni s posebnih slovenskih vidikov razločevati med različnimi tipi evropskega humanizma, ki so v 15. in 16. stoletju razgibavali zavest Evrope.

Naslednja razprava se osredotoča ob enem izmed središčnih vprašanj označenega problemskega kompleksa, ob vprašanju, koliko in $\mathrm{v}$ čem se je miselnost Erazma Rotterdamskega odrazila v pojmovanjih in v književnem delu prvega slovenskega pisatelja. Obravnava vprašanja o Erazmovi duhovni prisotnosti v slovenskem prostoru pa ne more mimo prikaza, kaj je bilo v slovenskem literarnem zgodovinopisju o tej temi rečeno. Preveritev sodb je metodološko nujna spričo spoznanja, da naša vednost o Erazmu samem in njegovi miselnosti ni napredovala $v$ istem koraku z raziskovalnimi postopki in rezultati na področju domače slovstvene tvornosti. Konkretno: Kidrič, ki je v začetku 2o-ih let prvi skrbneje in po zamišljenem načrtu pregledoval Erazmovo miselnost, da je po tem začrtal povezavo $\mathrm{s}$ Trubarjem, se je $\mathrm{v}$ splošnih oznakah velikega humanista naslanjal na proluthrovsko monografijo Franza Sticharta iz 1. 1870. Ne glede na časovno okolnost je bil Kidričev raziskovalni rezultat za svojo dobo v polnem pomenu besede odkrivateljski. Kritično in problematično pa je, če se sodobna študija, v kolikor govori o Erazmu, ni premaknila preko Sticharta in preko kliširanih kompendijskih sodb. To se je zgodilo v sicer vestno zastavljeni disertaciji Franceta Oražma Dogmatični nazori Primoža Trubarja in njegova odvisnost od početnikov reformacije (1964). Vedeti je treba, da so v zadnjem času tudi na katoliški strani premagali nekatere zelo pavšalne oznake Erazmove ideologije, če že ne upoštevamo dejstva, da je literatura o Erazmu v zadnjih desetletjih občutno narasla.

Drugi razlog, ki je pokrenil našo študijo, je drobno opozorilo, da na področju protestantke književnosti - kaj šele na drugih področjih našega slovstva - še zmerom ni dovolj upoštevano ali ne dovolj kritično 
ovrednoteno vse razpoložljivo kulturnozgodovinsko gradivo. Tudi v obdobju drugačnih posegov in prodorov v plasti slovstva ohranjajo, hočemo ali nočemo, kulturnozgodovinsko motivirane in informirane raziskave svoj pomen.

\section{I}

Prijateljeva omemba Erazma v nemško pisanem pregledu slovenske književnosti, ki je bil objavljen v ruskem (1904-06) in v srbskem prevodu (1906, 1920), je precej splošna in skopa. Medtem ko je mladi literarni zgodovinar $v$ razgretem delovnem zagonu jasno in zanesljivo očrtal pomen dunajskega humanističnega žarišča za vladanja cesarja Maksimilijana in opazil, da se je tod navzel Peter Bonom humanistične miselnosti, je Erazmovo ime navedeno na robu, tako kot Huttenovo, v zvezi s kritiko razvad in napak v katoliški cerkvi. Tudi pozneje, ko se je Prijatelj še enkrat in tudi tokrat le priložnostno, za Trubarjev jubilej, ukvarjal z vprašanji slovenske protestantske književnosti, ni našel časa, da bi se poglobil $\mathrm{v}$ vprašanje odnosov med humanizmom in protestantizmom. Pri Prijateljevi zasnovi eseja O kulturnem pomenu slovenske reformacije (1908) so bili bolj ko kateri drugi odločujoči narodnokulturni aktualni nagibi, zato se je trudil, da bi dokazal trajno vrednost protestantske književne dejavnosti na Slovenskem.

Določneje in v konkretni povezavi se je dotaknil razmerja ErazemTrubar nastopajoči Kidrič v študiji Primož Trubar, objavljeni v podlistku celjske Domovine (1908). Dasi je bil spis - enako kot Prijateljev - zasnovan kot aktualistična obramba narodnokulturnega pomena prvega slovenskega pisatelja, je vendarle $\mathrm{v}$ Kidričevem priložnostnem in znanstvenopoljudno uglašenem sestavku stopila tematika Erazmovega vplivanja polnopravno v slovensko literarnozgodovinsko obravnavo. Sklicevaje se na Trubarjevo pričevanje, da je tržaški škof Bonomo razlagal svojim klerikom Vergila, Erazma in Kalvina v italijanskem, nemškem in slovenskem jeziku, je Kidrič postavil domnevo, o škofovi pobudi, da je njegov gojenec iz dolenjske Rašice jel razmišljati o potrebi slovenskega pisanja. 
Mogoče je Bonomo Trubarja tudi opozarjal, koliko bi koristil slovenskemu dušnemu pastirstvu mož, ki bi dvignil slovenski jezik do časti pismenega jezika. ${ }^{4}$

Isto domnevo o sugestiji škofove slovenske razlage je Kidrič ponovil v ostrem polemičnem nastopu Epilog $k$ Trubarjevemu zborniku $u^{5}$ in v članku o Bonomu za Slovenski biografski leksikon. Značilno je za literarnega zgodovinarja Kidriča, da se v svojem mladostnem spisu o Trubarju ni zadovoljil $z$ naštevanjem ali opisovanjem zunanjih dejstev, marveč je hkrati skušal ugotavljati miselne zveze. V našem primeru to pomeni, da ga je zanimala vsebina Erazmove miselnosti, ki jo je mlademu Trubarju posredoval tržaški škof. Treba pa je reči, da je Kidrič vse od začetka gradil zaključke iz drobnih delov, postopno.

V spisu Primož Trubar beremo naslednje:

Čeravno je bil študiral Erazmove Parafraze, kjer se ta potujoči učenjak, ki je iskal v biblijskih povestih le alegorično izraženih idej, ni zbal trditve, da so se mogli apostoli motiti, je ostala zanj biblija od sv. Duha diktirano sv. pismo v pravem pomenu besede. ${ }^{6}$

Odštejmo neustrezno oznako "potujoči učenjak«, kar Erazem kljub pogostim selitvam ni bil, in postavimo pomišljaj ob »alegorično izraženih idejah «, kar bi terjalo kompleksno razpravo. Lahko pa prisluhnemo Kidriču, da sta si: Erazem in Trubar ustvarila v enem drugačen odnos do biblije, prvi predstavlja predvsem kritičnega misleca, drugi pobožnega vernika.

K problemu Erazem-Trubar se je Kidrič vrnil v obsežni, metodično vzorni analizi Ogrodje za biografijo Primoža Trubarja (1923) ${ }^{7}$. Izhajajoč iz načela, da je treba vse gradivo kritično preveriti, se je lotil vprašanja Erazmovega vplivanja v zvezi s podatkom o branju Parafraz. Potem ko je naštel in pregledal, katere so bile izdaje Parafraz do 1. 1530, to je do

4 Ur. M. Rupel, Slovenski knjižni zavod, Ljubljana 1951, str. 30. Naši zapiski, VI 1909, str. 170.

5 Naši zapiski, VI 1909, str. 170.

6 Gl. pod 4: str. 27.

7 Razprave Znanstvenega društva za humanistične vede, I, 1923, str. 179-272. 
Trubarjeve verske preusmeritve, je želel razbrati, katere ideje, razložene v Parafrazah, so na Trubarja naredile odločilen vtis. Kot smo že bežno omenili, je svojo razčlembo Erazmovih idej oprl na Stichartovo obsežno razlago. Zanimalo ga je tudi, kdaj se je Bonomo seznanil z Erazmovimi spisi, in sklepal, da pride v poštev čas njegovega bivanja na dunajskem dvoru, torej pred nastopom na mestu tržaškega škofa.

Matija Murko se s podrobnim gradivskim raziskovanjem slovenske protestantske književnosti sicer ni utegnil ukvarjati, zato pa je prispeval pomemben znanstven delež s sintetičnimi pregledi in $\mathrm{s}$ kritičnimi pretresi. Njegova zasluga je, da je kot prvi vzporedno obravnaval reformacijo in protireformacijo pri jugoslovanskih narodnih. $\mathrm{V}$ delu, ki je lahko še danes dragocen vodič, je mimogrede opozoril na željo Erazma Rotterdamskega, da bi mogli biblijo brati tudi Turki in Saraceni, željo, ki so jo skušali jugoslovanski protestanti vsaj deloma uresničiti. ${ }^{8}$

V nadaljnjem delovanju so Kidriča drugi načrti odmaknili od širših zastavitev na področju slovenske protestantske književnosti, toliko je še utegnil, da je v Zgodovini slovenskega slovstva (1. sn., 1929) strnil dognanja in jih včlenil v celotno razvojno podobo. Zanimivo je ugotoviti, da se je Kidričev eksaktni ustvarjalni duh neredko s pridom predajal tudi domnevam, katerih ena, vzeta $v$ humanistično-protestantski zvezi, je doživela dvajset let pozneje sijajno dokumentarično potrditev. V Zgodovini je Kidrič napisal tale stavek:

Nedvomno je poleg agitacijske vneme in protestantske miselnosti delovalo pri njem (tj. Trubarju) tudi ugibanje o sramoti slovenske zaostalosti, ko je oblikoval prvo misel o pisanju slovenske besede. ${ }^{9}$

Dokument, ki je prišel v javnost za jubilej slovenske knjige l. 1951, je pismo Trubarja (in Krelja) Bohoriču iz $1.1565 .{ }^{10} \mathrm{~V}$ njem se Trubar razodeva kot narodni prosvetitelj in kulturni delavec, ki s svojim književnim delom hoče služiti premagovanju splošne zaostalosti, prebujati sloven-

8 Die Bedeutung der Reformation $u$. Gegenreformation fur das geistige Leben der Südslaven, Frag u. Heidelberg, 1927, str. 10.

9 Str. 24/25.

10 M. Rupel, Novo Trubarjevo pismo, Slavistična revija, IV/1951, str. $111 \mathrm{~s}$. 
ske množice in v njih netiti spoštovanje do lepih umetnosti in duhovne izobrazbe.

Ta izjava ni samo povzdignila zanešenosti jubilejnih dni, marveč je očividno pomagala premakniti težišče razpravljanja od Trubarja - protestanta k Trubarju, ki je bil v nekem smislu tudi humanist. Aktualistično poantirani esej Bratka Krefta Osebnost Primoža Trubarja (1951) je zgovoren dokaz nove kulturnofilozofske interpretacije: Trubar je bolj humanistični reformator kot fanatični lutrovec, kot so ga pogosto označevali, je v bistvu nedogmatična narava, saj lahko naštejemo v njegovem življenju nemalo spopadov s protestantskim dogmatizmom, skratka, njegovo delo je slovenska formulacija protestantizma. V smislu te razlage ni daleč pot k Erazmu, in res je Kreft napisal:

Humanizem in racionalizem Erazma Rotterdamskega je realizem dolenjskega kmečkega sina le še podkrepil, čeprav ga je pozneje protestant Štefan Konzul napadel, da je sanjač. In še nekaj je moral Erazem Rotterdamski podkrepiti v Trubarju: toleranco ..."

Tudi Dušanu Pirjevcu, ki je s kritično ostrino ocenjeval Zgodovino slovenskega slovstva I, pomeni omenjena Trubarjeva izjava iz 1.1565 izrazito humanistično sporočilo.

Zaslužni zbiratelj protestantik in pisec številnih gradivskih študij je v orisu protestantske književnosti v pravkar omenjeni Matičini zgodovini ostal v okviru Kidričevih ugotovitev: Erazem-Bonomo-Trubar, medtem ko je njegova oznaka Erazma zelo medla in prekomerno pavšalna, trdi med ostalim, da »V njem ni bilo globine verskega občutja $\aleph^{12}$. Rupel je to trditev od nekod nekritično povzel. Zato pa je glede na naš problem stopil v monografiji Primož Trubar (1962) preudaren in tehten korak naprej: poiskal je ustrezna mesta v knjigi parafraz in razlago, ki je bila dotlej oprta na posredno predmetno literaturo, naslonil na prvi vir. To dejanje ga je peljalo do eksplicitne trditve: »Ob Erazmovih Parafrazah pa se mu je vsadila v srce tudi želja, da bi se sveto pismo prevedlo v slovenščino. « ${ }^{13}$

11 Nova obzorja IV/1951, str. 508; ponatis, isti avtor, Portreti (1956).

12 Zgodovina slovenskega slovstva I, Slovenska Matica, Ljubljana, 1956, str. 192.

13 Str. 25. 
Literarnozgodovinski sintetični deli, ki sta nazadnje problemu Erazem-Trubar posvetili polno pozornost, sta Antona Slodnjaka Slovensko slovstvo (968) in Jožeta Pogačnika Zgodovina slovenskega slovstva I (1968). V Slodnjakovem prikazu, ki poudarja veličino Erazmovega genija (»živa človečnost, « »humanost Erazmovih dokazov«) je poleg razlagalca - posrednika Bonoma upoštevan Trubar kot prav tako samostojen bralec del znamenitega humanista. ${ }^{14}$ Med vsemi je doslej pri Trubarju najširše razprl sfero možnega Erazmovega vplivanja pri Trubarju Pogačnik. Sodi namreč, da »Trubarjevo duhovno obzorje kljub vsemu (tj. vplivanosti od drugih strani) največ dolguje študiju spisov Erazma Rotterdamskega. ${ }^{15}$

\section{II}

Prvič je omenjeno Erazmovo ime v predgovoru (posvetilu) prvega Trubarjevega svetopisemskega prevoda, "autore Matthaeo, nunc primum uersum in linguam Schlauicam « (1555). Predgovor, namenjen "pravi cerkvi božji tiga slovenskiga jezika«, obsega poleg drugega sporočilo o tem, kako sta se podpisana V(ergerij) in T(rubar) lotila prevajanja:

... de mi v le-tim naśim prevračenu smo veden imejli pred sabo ta pravi studenec tiga noviga testamenta, kir je grśko pisan; raven tiga smo tudi gledali na tu prevračene tih novih inu starih vučenikov, kateri so ta nov testament iz tiga grśkiga $\mathrm{v}$ ta latinski, nemśki inu v laśki preobrnili, nerveč pak na Erazmov Roterdamov testament, h timu so nom nega annotationes silnu pomagale. ${ }^{16}$

Sporočilo o začetku prevajanja biblije, najznamenitejše književne akcije slovenskih protestantov, je pomembno v več pogledih in skladno $s$ tem odpira več vprašanj. $\mathrm{V}$ našem tematskem območju je prvo tako vprašanje, kakšna neki je zveza med Erazmovo izdajo izvirnega grške-

14 Str. 26, 30.

15 Str. 117.

16 Slovenski protestanski pisci (ur. M. Rupel), Ljubljana 1934, str. 13. 
ga besedila $\mathrm{z}$ latinskim prevodom, prvič izšlo 1516, in med slovenskim Trubarjevim Matevžem.

Ob vprašanju se je s kritičnim dvomom ustavil že Ivan Grafenauer, ${ }^{17}$ ki je, sklicevaje se na znani podatek, da Trubar ni obvladal grščine, zanikal, da bi prevod Matevža imel kakšno zvezo z grškim izvirnikom. Potem ko je primerjal tekstovno gradivo, je prišel do zaključka, da je Trubar prevajal v glavnem po nemški Luthrovi izdaji in si je na nejasnih mestih pomagal z vulgato. Podatek iz predgovora 1.1555 je zlagan, kar gre predvsem na račun Vergerijevih samovšečnih mahinacij, hvalisanja in igre imenitnega videza pred javnostjo. Po Grafenauerjevi sodbi je značilno, da je Trubar v široko zasnovanem predgovoru prvega dela novega zakona (1557), torej potem, ko sta se z oblastiželjnim Italijanom že razšla, in pozneje, vsak namig na grščino povsem opustil. Drugi, Mirko Rupel, ${ }^{18}$ je umeval podatke iz sporočila o prevajanju drugače: Trubar res ni znal grški, dvoma o tem, da je prevod njegov, seveda ne more biti, saj sam Vergerij priznava, da slovenščine ni bil zmožen; kljub vsemu temu sodelovanje bivšega koprskega škofa pri prevodu ne more biti zaobseženo v samih organizacijsko-tehničnih poslih, k prevodu je vsaj toliko prispeval, da ga je, vešč grščine, pregledal. Čeprav je Rupel v precejšnji meri omilil Grafenauerjevo sodbo, je hkrati priznaval, da je v omembi 1. 1555 grški izvirnik "preveč poudarjen«, ker je pač na ta način Vergerij hotel pridobiti prevodu »večjo veljavo. « Navzlic razlikam sta obe navedeni razlagi nemalo zožili trditev: »nerveč pak (smo gledali) na Erazmov... nov testament.«

$\mathrm{Ob}$ navedenem primeru ne moremo mimo očitnega spoznanja, da določene predstave iz stare književnosti, ki smo jih umevali preveč po črki ali po vtisu, terjajo strogega kritičnega razbora. Saj po tolikerih naporih, ki so jih obravnavam protestantske književnosti posvetili številni odlični raziskovalci, še ni mogoče odgovoriti na vprašanja: kako je Vergerij "pregledoval« Trubarjev tekst Matevža, ko po lastnih besedah slovenski ni videl? Z vzporejanjem več prevodov? Ob sprotnem posvetovanju s prevajalcem?

17 O Trubarjevem prevod uevangelijev; Dom in svet XXVII/1914, str. 297-303.

18 Primož Trubar, Življenje in delo, Ljubljana 1962, str. 91. 
Enako ostaja nejasno v naš čas, kako je razumeti dvakratno Trubarjevo navajanje Erazmovih »annotationes «, o katerih trdi v predgovoru 1. 1555, da so jima $z$ Vergerijem »silnu pomagale«, in ponovno sklicevanje nanje dve leti pozneje. Tega vprašanja se Grafenauer ni dotikal, najbrž zavoljo tega ne, ker se je zavedal, da tu filolog in zgodovinar sama, brez teologovega (biblicistovega) sodelovanja ne moreta pripeljati do zanesljivih sklepov. Edini Rupel je iskal bibliografski vir za navedene "annotationes« in je v opombah $\mathrm{k}$ monografiji zabeležil naslednje:

Annotationes so dodatek $\mathrm{k}$ Erazmovi izdaji grškega novega zakona $\mathrm{z}$ latinskim prevodom; njih naslov glasi: Novum instrumentum omne, diligenter ab Erasmo Roterdamo recognitum emendatum... una cum Annotationibus, quae ratione mutatum sit.

Komentator pa ni omenil, da poleg tega »dodatka« obstaja še samostojna, zelo obsežna knjiga, izšla 1522: Des. Erasmi Roterodami in novum testamentum ab eodem tertio recognitum, Annotationes...

Leto 1557, leto izdaje Trubarjevega velikega opusa Ta prvi dejl tiga noviga testamenta (štirje evangelisti z dejanji apostolov, večni koledar, dogmatični uvod, imenovan Ena dolga predguvor, register $\mathrm{s} » k$ ratko postilo«) pomeni vrhunsko točko v Trubarjevem iskanju sveta in opore v Erazmovi šoli. Sicer pa se je tokrat Trubar prvič s polnim imenom in s prirojeno odprto neposrednostjo obrnil na "vse pobožne kristjane« v slovenskih deželah. In se je razgovoril o svojem delu in načrtih, kot, če že ne prej, tudi pozneje redkokdaj.

Erazmovo ime je v obsežnem, nemško pisanem predgovoru navedeno izrecno štirikrat, posredno zvezo z njim nakazujeta vsaj še dve mesti. Prvič, ko se je s sinovsko hvaležnostjo spomnil dobrotnika Petra Bonoma, ki mu je $\mathrm{z}$ razumevanjem in naklonjenostjo odprl pot do višje in stvarne izobrazbe.

Imenovani tržaški škof me je vzgajal, učil in pošteno navajal k popolni pobožnosti; na svojem dvoru meni in drugim razlagal poleg Vergila tudi 
Erazmove parafraze in Calvinove institutiones v laškem, nemškem in slovenskem jeziku. ${ }^{19}$

$\mathrm{Na}$ robu pa je počastil spomin dragega pokojnika $\mathrm{z}$ gesto, vredno Bonomove humanistične šole, namreč, navedel je verz iz Vergilove Eneide: »Et bene apud memores veteris stat gratia facti.» (Pri takih, ki ne pozabljajo radi, trdno stoji zahvala za nekdanjo dobroto.) Tu smo pri osnovnem podatku, ki je proučevalce Trubarjevega pisateljstva od Kidriča dalje usmerjal v tematski krog Erazma Rotterdamskega. V našem dosedanjem izvajanju so bile razlage vsaj obrisno nakazane, dodati velja, da je Kidrič glede na datum izida Calvinovih Instiutiones (tako Trubar; Kidričev pravilni naslov: Institutio religionis christianae, l. izd. 1536) opazil dve obdobji,v katerih je Trubar bil deležen sadov škofove humanistično-reformatorske usmerjenosti.

Slovenska literarna znanost se je tolikanj ustavila ob dragocenem podatku, da ni dovolj opazila še nekaterih ilustrativnih primerov, ki v istem predgovoru prikazujejo Trubarjevo sorazmerno razpredeno in intenzivno zanimanje za Erazma. Tako, ko na široko razlaga in utemeljuje, kako da se je lotil prevajanja svetega pisma brez znanja hebrejščine in grščine. Iznenada, iz sveže ohranjenega spomina, mu kot stilizacijska poživitev kane stavek:

... da človek težko in nezanesljivo s tujimi očmi gleda in s tujimi nogami hodi, kakor pravi Erasmus o sv. Hilariju, ki tudi ni znal hebrejski. ${ }^{20}$

Vir za navedbo iz Erazma ne more biti kaj drugega kot ena izmed njegovih številnih izdaj cerkvenih očetov, galskoromanski Hilarij, iz začetka 2o-ih let.

Še dva cerkvena očeta sta dobila mesto v istem predgovoru, ne da bi bil ob njih Erazem posebej imenovan, vendar je samo ob sebi jasno, da ju je mogel Trubar poznati iz takrat aktualnih in najbolj dostopnih Erazmovih izdaj: to sta »divus« Hieronymus, 1516 ali v novi izdaji 1524, in Janez Krizostom v latinskem prevodu 1530. Na Jeronima, ki je Erazmu

19 Gl. pod 16: str. 20.

20 Gl. pod 16: str. 25. 
pomenil vrhunec biblijske znanosti, meri na koncu predgovora opazka, s katero želi njegov pisec spodbuditi k branju svetega pisma: »In sv. Hieronim pravi, da so kmetje pri Betlehemu, kadar so orali, prepevali Davidove psalme...« Pri navajanju Janeza Krizostoma je Trubar lokacijsko določnejši, govori o njegovi deveti pridigi (o listu Kološanom) in jo po ideji povezuje z enako Erazmovo mislijo v delu Paraclesis, naperjeno, da spodbuja k branju biblije:

... tu boste našli, kako ta dva sveta in učena božja moža pošteno in odločno učita in opominjata po božji besedi in po sv. pismu, naj vsakdo, posvetnjak oziroma laik, plemenit in neplemenit, meščan, kmet, rokodelec, sel ali pastir na polju, neprenehoma bere sv. pismo in naj iz njega povsod govori, poje in pripoveduje. ${ }^{21}$

Misel, kakor je v Trubarjevi parafrazi povzeta po Erazmu, sodi med tiste ideje, ki jih je Erazem posebno vneto razširjal. Poleg omenjenega spisa Paraclesis jo lahko beremo, morda rahlo predrugačeno, a smiselno vendarle isto, npr. v uvodu Erazmovega najznamenitejšega biblijskega dela, tj. v posvetilu "pobožnemu bralcu " grško-latinske izdaje novega zakona, podobno v enako naslovljenem posvetilu Parafraz 1524 in še drugje. Tako da ni toliko bistveno, ali je imenovan »kmet, rokodelec, sel ali pastir na polju« (pri Trubarju) ali »kmet za plugom in tkalec pri statvah... popotnik na cesti« (tako Paraclesis ${ }^{22}$ in podobno "pio lectore ${ }^{23}, 1516$ ). V našem primeru ne gre prezreti, da je Trubar pri navajanju ideje imenoval določeno Erazmovo delo, ne le Erazma nasplošno.

Kar še posebej pada v oči, je to, da se v Trubarjevem opusu pojavlja Luthrovo ime, najsi je iz dela velikega reformatorja črpal že za svojo prvo knjigo, pozneje ko Erazmovo (Luther omenjen 1557). Na mestih pa ju najdemo imenovana drugega ob drugem, kar ni brez pomena. Prvi tak primer je, ko Trubar v pismu svojemu podporniku kralju Maksimilijanu

21 Gl. pod 16: str. 28. Po vsej verjetnosti se Trubar sklicuje tudi na Ciprijana (1558, 1562) in na Avguština (1562), ki sta izšla v Erazmovi izdaji.

22 J. Huizinga, Erasmus, Basel 1951, str. 124/125.

23 Erasmus v. Rotterdam, Briefe, izd. in uvod W. Köhler, Leipzig 1938, XXXI. 
2. jan. 1560 opravičuje napake in pomanjkljivosti v lastnih tiskih s tem, da se je to pripetilo že drugim in to najuglednejšim:

... dass etwas in trucken und im corrigieren ist übersehen... und ain wort improprie auss mangel der sprach oder sonst unbedächtlich möchte verdolmetscht worden sein. Sollichs ist auch den LXX, Symmacho, Aequilae, Iheronimo, Erasmo, Luthero, und andern widerfaren. ${ }^{24}$

Malo je verjetno - da ne rečemo: ni verjetno -, da bi Trubar mogel imeti v razvidu Erazmovo publicistiko v široki vrsti del, vendar je vredno omeniti, da najdemo podobno misel o naključnih napakah $\mathrm{v}$ Hieronimu in še pri drugih veljavnih avtorjih tudi pri Erazmu. Naj navedemo samo en primer. V polemičnem spisu proti Luthru (replika na De servo arbitrio), naslovljenem Hyperastistes (1526), je Erazem poudaril:

Želim, da bi Ti in Tvoji zvedeli, najprej, kar zadeva sveto pismo, da sem pri razlagi pač lahko tu in tam pogrešil, kar, kot poveš, se je tu in tam zgodilo tudi Hieronimu ...

Posvetilo istemu, kralju Maksimilijanu, napisano za glagolski prvi del novega testamenta (1562), je Trubarju še enkrat dalo priložnost, da se je razživel kot poročevalec o verskih in drugih razmerah v južnih slovanskih deželah. Želeč vladarja informirati »o ubogih kristjanih, ki so prisiljeni živeti pod turškim trinoštvom v Bosni in njeni okolici, v Srbiji, Bolgariji in v sosednih deželah«, je na široko pripovedoval o pravoslavni liturgiji in pri tem ni pozabil omeniti, da je njihova maša tista maša,

ki jo je Erazem Rotterdamski prevel pred leti iz grščine v latinščino in ki jo nahajamo na koncu petega zvezka spisov Ivana Krisosoma, knezoškofa carigrajskega. ${ }^{25}$

Podatek da slutiti, da je Trubar Erazmove izdaje cerkvenih očetov neredko jemal $v$ roke. $V$ istem predgovoru sta med predlogami virov pre-

24 Th. Elze, P. Trubers Briefe, Tübingen 1897, str. 38.

25 Gl. pod 16: str. 54. 
vajanja našteta Erazmov in Luthrov prevod, ki da jima prevajalci najbolj sledijo. ${ }^{26}$

Poslej se v Trubarjevih delih sklicevanja na Luthra množe, Erazmovega imena pa ni več zaslediti. Omenjeno bodi še to, da je protestantski šolnik v Ljubljani Lenart Budina rabil kot pomoček pri študiju latinske in grške frazeologije 4. izdajo Erazmovih Chiliades.

Ob Trubarjevem zanimanju za Erazma in glede na njegovo poznanje del je dokumentirano jasno eno, da je Trubar v prvi dobi svojega pisateljevanja precej črpal iz Erazma, vendar, da so vsa njegova sklicevanja na Erazma in na avtorje, ki jih je humanistični učenjak izdajal, izbrana in uporabljena $\mathrm{v}$ izrazitih in izključnih biblijskih povezavah. ${ }^{27}$

\section{III}

Na naslovni strani druge Trubarjeve knjige, abecednika z malim katekizmom (Tübingen 1550), stoji napis: Et omnis lingua confitebitur Deo. Isti stavek apostola Pavla (Rimljanom XIV) je natisnjen v petih jezikih in v različnih grafikah (vštevši glagolsko in cirilsko) na naslovni strani Bohoričeve slovnice (Arcticae horulae, Wittenberg 1584).

Navajanje Pavlovega stavka je imelo v tedanjih slovenskih razmerah dvojno, narodnokulturno in verskoidejno logiko: protestantski pisatelji

26 Gl. pod 16: str. 65. Prim. l. Polovič, Evangelij sv. Matevža v protestantskem „Prvem delu Novega Testamenta" iz l. 1562, Zbornik Matice Slovenske X, 1908, str. 56-73 (hrvatska prevajalca rabila Trubarjev prevod, Luther sam je temeljil na 2. Erazmovi izdaji iz 1519).

27 Drugače, a zame nesprejemljivo: J. Pogačnik, Zgodovina slovenskega slovstva, I, Maribor 1968, str. 117/118 in 139/140. Popraviti velja dve netočnosti: Erazmova slika ni odtisnjena $\mathrm{v}$ Trubarjevi izdaji celotnega novega zakona (1582), marveč na platnicah knjige, tiskane v biblijskem zavodu v Urachu (A. Gspan, Prispevek $k$ ikonografiji P. Trubarja, Trubarjev zbornik, Ljubljana 1952, str. 153), in na lesenih platnicah izvoda novega zakona, ki je v mestni knjižnici v Schaffhausnu (M. Rupel, Nove najdbe naših protestantik XVI. st., Lj. 1954, str. 14). in podatek o Hieronimu (ta ni bil "poganski učenjak«). Popravek terja tudi napačna trditev K. Georgijevića, da je Trubar prevajal Erazma (gl. Hrvatska književnost od 16. do 18. stoljeca u sjevernoj Hrvatskoj i Bosni, Zagreb 1969, str. 24). 
so lahko na ta način s stavkom iz najveljavnejšega vira, iz svetega pisma, utemeljevali ne le pisanje v slovenščini, marveč prav tako njeno uvedbo kot bogoslužnega (liturgičnega) jezika. Vendar je treba ta dva razloga, kakor koli sta značilna, včleniti v širši kompleks okoli apostola Pavla, kajti sveti Pavel sodi med tista imena biblijskih pisateljev, na katera so se oboji, humanisti in reformatorji, najpogosteje sklicevali.

Nekaj primerov, kako sta vodilna protagonista humanizma in reformacije v prvi polovici 16. stoletja, Erazem in Luther, črpala iz krščanske ideologije apostola - filozofa Pavla. Že v prvotnem predgovoru za Enchiridion militis christiani (1501) je pozival Erazem bralca: »Predvsem se seznani s Pavlom! $\aleph^{28}$ In, serijo slovitih Parafraz (1517-1523, nato ponatisi) so uvedla tolmačenja Pavlovih listov, ali, omenjeni Paraclesis našteva Erazem takoj za evangeliji Pavlova pisma, ki naj bi jih brale celo vse žene in naj bi jih prevedli v vse jezike. Podobno Luther. Ob Pavlovi besedi o pravičnosti božji, ki se razodeva v evangeliju, se je zganil njegov metafizični nemir, ki ga je gnal v brezprizivno vztrajanje pri osebno spoznani resnici. Enako tisti, ki so se učili pri Erazmu ali Luthru ali pri obema. Pri Trubarju so posejana sklicevanja na Pavlove stavke začenši s katekizmom in abecednikom preko »cerkvene ordninge« vse do zadnjih knjig. Le en primer:

O avtorju, vsebini in neizrekljivi koristi lista do Rimljanov, ki ga vsi pobožni in učeni imajo in silno cenijo kot pravi in poglavitni del novega testamenta in najčistejši evangelij ... sem ... že prej govoril in razlagal ... $(1560){ }^{29}$

Erazem in Luther sta dajala in priznavala svetemu pismu najvišjo avtoriteto v teološko-filozofskem in v moralnem smislu, kar velja tudi za Trubarja. Kakor je ta načelna postavka jasna in nesporna, se vendar v njenih vsebinskih globinah in ozadjih skrivajo občutljive razlike, ki so ločile humanista od reformatorja. Zato se velja v naši razpravi, ki je urejena glede na razmerje Erazem-Trubar, omejiti na čimbolj razvidna dognanja.

28 Gl. pod 23: str. 76.

29 Gl. pod 16: str. 42. 
Znana Erazmova misel, ki je docela prevzela in prepojila Trubarjevo tvorno voljo, je izražena v zahtevi, da bodi sveto pismo dostopno vsakomur. V Trubarjevi izpeljavi Erazmove ideje je to pomenilo: tudi Slovencem in Hrvatom, o čemer je spregovoril v predgovoru za Ta prvi dejl tiga noviga testamenta:

... ko sem še pri vas pridigal v slovenskem jeziku iz latinskih in nemških knjig, (sem) često vzdihnil in vzkliknil k Bogu, naj se zaradi posvečenja svojega imena in razširitve svojega kraljestva milostno ozre tudi na naš ubogi, preprosti, dobrosrčni slovenski narod, naj mu prizanese in ga obdari z veliko milostjo in darom, da bi se tudi njegov jezik pisal in bral, kakor jezik drugih narodov, ter da bi se sv. pismo in dobre krščanske knjige prav prevedle in natisnile $\mathrm{v}$ slovenskem in hrvatskem jeziku. ${ }^{30}$

Želja, da bi Slovenci (in Hrvati) dobili sveto pismo, se je potemtakem spočela v Trubarju še pred njegovim pobegom v Nemčijo, torej, še preden se je zavestno in dokončno vključil v organizirano Luthrovo cerkev augsburške veroizpovedi. Drugače povedano, izvora tele usmerjenosti je treba iskati pri Erazmu, s katerega idejami je mladega klerika seznanil v Trstu Bonomo. Slovenska literarna zgodovina je to razlago sprejela, nazadnje je Mirko Rupel šel iskat osnovni vir, v tekst Parafraz, in je v monografiji poleg drugega objavil v prevodu odlomek, kjer je izražena omenjena Erazmova zahteva naravnost. Jasno je, da bi podobnih mest lahko nabrali v Erazmovih spisih za več ko polno perišče. Da pokažemo, s kako močjo besede in misli je razpolagal Erazem, navedemo nekaj stavkov v izvirniku (tudi zato, ker zadnjih stavkov, ki motivirajo prevajanje s Kristusovo željo, kar za Erazma ni neznačilno, v slovenskem prevodu ni):

Quidam piaculum arbitrantur, si sacri libri vertantur in linguam Gallicam aut Britannicam. Sed Evangelistae non veriti sunt graece scribere, quod Christus syriace locutus est. Neque latini veriti sunt apostolorum sermonem in Romanam linguam vertere. Equidem cupiam in omnes ver-

30 Gl. pod 16: str. 17. 
ti linguas. Cupit Christus suam philosophiam quam latissime propagari. Pro omnibus mortuus est, ab omnis cognosci deslderat..$^{31}$

Slovenci, ki so nam enega temeljnih tekstov individualnega književnega razvoja, Biblijo (1584), dali protestanti, navadno niti ne pomislimo, da začetki sistematičnega prevajanja svetega pisma segajo še več ko sto let pred Luthra. Pomembna opozorila na vrednost prevajanja biblije na narodne, ljudstvu razumljive jezike, najdemo že v 14. stoletju (Wiclif, Matej z Janova), medtem ko so se prvi knjižni prevodi pojavili že med 1466 in 1487, in sicer v nemščini, holandščini, italijanščini in francoščini, v Augsburgu so izdali celo biblijo s slikami. Skratka, še preden se je dvignil Luther proti Rimu, bi lahko našteli v Evropi ne le ducat, marveč sto biblij. ${ }^{32}$ Pri Madžarih so npr. prve prevode pripravili t. im. erazmovci, seveda najprej liste svetega Pavla (1533, prev. Komjáthy Benedek), nato evangelije in novi zakon (1541), celotna biblija pa je bila prevedena posebej za protestante (1590, prev. Károli Gáspár) in za katoličane (1626, prev. Káldi György).

Poznavalcem Trubarjevega dela je znano, da je slovenski reformator zahteval za verski nauk, ki ga je $\mathrm{z}$ vso prizadetostjo goreče razširjal, oznako "prava vera» (1550), "prava evangeljska krščanska vera» (1557), "prava krščanska vera« (1561) ipdb. Reformatorji so oznanjali povratek k nepotvorjeni razodeti resnici, ki so jo po njihovi sodbi različni samozvani varuhi pokvarili. Toda, kje je vir prave, zanesljive razlage? Erazem, ki je sicer na vso moč spoštoval Hieronima (zelo pogosto mu prideva oznako »divus« - »božanski«), je pokazal na grški izvirnik kot na avtentično besedilo. Zanimivo je, da najdemo tudi pri Trubarju primere, ki govore o tem, da je priznaval prvo mesto grškemu izvirniku. V predgovoru za

31 Erasmus Roterodamus, Tomus primus paraphraseon, Basilae 1524, str. a5b. Prim. Ruplov prevod odlomka v monografiji Primož Trubar, str. 25: »... Tudi Latinci se niso plašili prevesti govorico apostolov v rimski jezik, in Hieronimus ni štel za prestopek zoper vero, ko je sveto pismo prelagal v dalmatščino..." Ad dalmatice: v izvodu v NUK v Ljubljani (št. 15463), ki je bil nekdaj last gornjegrajske škofijske knjižnice, je nad to besedo napisano: superstitio!

32 Tenenti-Romano, Die Grundlegung der modernen Welt, Fischer-Weltgeschichte 12, Frankfurt M., str. 257/258. 
Matevža beremo: "...smo veden imejli pred sabo ta pravi studenec tiga noviga testamenta, kir je grško pisan. « In ko se je v obsežni spremni besedi prvega dela novega zakona spominjal težav in nevšečnosti, ki so jih imeli z iskanjem prevajalca oziroma prevoda biblije v hrvaščini, je pripomnil za vsak primer, če bi kako odkrili že izgotovljeni glagolski prevod:

... da bi se tista biblija skrbno pregledala ob novih prevodnih (kajti stara latinska biblija je na mnogih mestih temna in nerazumljiva, kakor pravijo vsi učenjaki) ... ${ }^{33}$

Več ko verjetno je, da je Trubar med temi učenjaki imel v mislih tudi Erazma, saj je znano, da je znameniti humanist ne samo enkrat izrekel kritično besedo o vulgati, da so teksti neusklajeni in tudi pokvarjeni.

Druga značilna poteza, ki povezuje Trubarja z Erazmom, je kritično zaostreno stališče do raznih pojavov povnanjenja verskega življenja. To zvezo je opazil že Kidrič, ko je v razpravi l. 1923 napisal: »...Trubar je začel nastopati proti romanju in ustanavljanju novih cerkva že 1. 1530, torej v času, ko ga v to smer še ni mogel kreniti vpliv Bullingerjevih ali Pellicanovih spisov, ki takrat še niso bili na svetlem, pač pa je mogel to storiti vpliv Bonomov. ${ }^{34}$ Bonomo se je na Dunaju seznanil z Erazmovimi deli ter je vcepil svojim klerikom odpor do romanj, češčenja svetnikov ipdb. Katera so ta Erazmova dela? Rupel je tudi za ta primer navedel v monografiji o Trubarju odlomek iz Parafraz, navedli bi lahko še Priročnik krščanskega vojščaka, Colloquia in seveda duhovito, iskrivo pisano Hvalnico norosti (1509), ki so jo piscu tolikeri verski ozkosrčneži in zagovedneži neusmiljeno strogo zamerili. ${ }^{35}$

Ali se je Trubar kritičnega racionalizma navzel med Bonomovo razlago Erazmovih Parafraz ali pa je še sam našel pot do branja del velikega humanista, ni bistveno. Sicer pa je znano, da so proti oblikam praznoverja in demoralizacije v cerkvenem življenju dvignili glas že mnogi pred Erazmom in je vsa ta kritika v končnem rezultatu rodila reformacijo.

33 Gl. pod 16: str. 24.

34 Gl. pod 7: str. 218.

35 J.-C. Margolin, Érasme par lui-même, E. du Seuil, Paris, 1965, passim. 
Trubarjeva kritičnost se je, ne glede na to, kakšni idejni momenti so stali ob njenem rojstvu, zlila $\mathrm{v}$ neko obliko praktičnega racionalizma. Kot ilustracijo naj navedemo njegov Katekizem $z$ dvejma izlagama (1575), ki je izrazito polemično ubran in v katerem je pisec nasul pisano množino slikovitih primer, $\mathrm{v}$ katerih $\mathrm{z}$ drastičnim izrazjem smeši različne verske manifestacije "papežnikov«. Mednje je uvrstil klasični primer svojega praktičnega nazora: kako je njegov oče dal na Rašici poslikati cerkev in kako so prišli Turki in uničili cerkev s slikarijo vred, iz česar izvaja pripovedovalec praktični življenjski nauk, da bi bil njegov oče bolje naložil tistih dvajset ogrskih zlatnikov (kolikor je plačal slikarju), če »bi bil ene štiri vole kupel inu tim bozim sosedom dal, de bi ž nimi orali, suje otroke živeli.. ${ }^{36}$

Vendar je problem kritičnega racionalizma širši in bi vodilo v poenostavljanje, če bi ga obravnavali ob nekih iztrganih primerih. Posebej še, če bi ga izolirali od verske ideologije. Kajti ne glede na temeljne razlike, ki ločijo strukturiranost Erazmove od Luthrove ali Trubarjeve misli, je pri vseh treh v središču miselnih procesov verska ideologija.

Verska ideologija pa kot vsaka ideologija kljub osnovnim principom in nekaterim dominantam ni nekaj nepremakljivega, nekaj v vsem enkrat za vselej danega in določenega. Tudi miselnost se giblje, razvija in premika težišča $v$ menjajočih se konstelacijah geopolitičnega prostora in sil zgodovine. Zato neka nazorska, z našo temo bolj ali manj povezana vprašanja sama po sebi terjajo širok uvid v ozadja oziroma upoštevanje mnogostranskega prepletanja silnic. Taka so vprašanja npr.: Trubarjevo nihanje med Zwinglijem, ki ga nekateri zavoljo njegovega simbolnega pojmovanja evharistije štejejo med racionalistične reformatorje, in med Luthrom, ali, do kod seže Trubarjeva toleranca in kje se začenja pravoverna »formula concordiae« ipdb.

Naposled velja omeniti še eno značilno potezo, ki je skupna Erazmu (kot humanistom na sploh) in Trubarju, to je: želja po znanju. Pojavne oblike tega stremljenja, s poudarkom na Trubarjevi skrbi za šolstvo je literarna zgodovina že večkrat pazljivo obravnavala, nazadnje Jože Pogačnik v prvi knjigi svoje Zgodovine slovenskega slovstva.

36 gl. pod 16: str. 128. 
Facit razprave: Trubarjevo naslanjanje na Erazma je poleg vsega drugega dokaz o evropskem utripu slovenskega človeka v prvih fazah našega narodno-kulturnega razvoja.

\section{Uredniška opomba}

V ponatisu originalnega prispevka smo odpravili očitne pravopisne in slovnične napake ter nedoslednosti. Citate smo tipografsko oblikovali skladno s celostno podobo in ureditvijo revije Stati inu obstati. Opozarjamo, da sta pri izvirnem natisu (stavku) iz glavnega besedila razprave izpadli sklicni številki za dve podčrtni opombi, katerih besedili sta sicer natisnjeni pod črto. Opombe v našem ponatisu so temu ustrezno preštevilčene in je njihovo skupno število krajše za dve. Gre za opombi:

25, na str. 93: F. Stichart, Erasmus v. Rotterdam, Leipzig 1870, $235 \mathrm{s.}$

28, na str. 94: J. A. Glonar, Iz mladosti Lenarta Budine, Časopis za zgodovino in narodopisje, XXIII/1928, str. 146.

https://doi.org/10.26493/2590-9754.14(28)183-201 